\title{
A super-spreader of SARS-CoV-2 in incubation period among health-care workers
}

Chaojie Wei ${ }^{1,3}$, Yufeng Yuan ${ }^{2}$ and Zhenshun Cheng ${ }^{1,3^{*}}$

\begin{abstract}
Since the coronavirus disease 2019 (COVID-19) identified in Wuhan, Hubei, China in December 2019, it has been characterized as a pandemic by World Health Organization (WHO). It was reported that asymptomatic persons are potential sources of severe acute respiratory syndrome coronavirus 2 (SARS-CoV-2) infection. We present an outbreak among health-care workers incited by a doctor who cared a patient with COVID-19 in a Hospital in Wuhan, Hubei, China, which indicates existence of super-spreader even during incubation period.
\end{abstract}

Keywords: Coronavirus disease 2019, Health-care workers, Super-spreader

To the editor:

Since the coronavirus disease 2019 (COVID-19) identified in Wuhan, Hubei, China in December 2019, it has been characterized as a pandemic by World Health Organization (WHO). Person-to-person transmission pattern of COVID-19 is obvious [1, 2]. Moreover, it was reported that asymptomatic persons are potential sources of severe acute respiratory syndrome coronavirus 2 (SARS-CoV-2) infection [3]. Here, we present an outbreak among health-care workers incited by a doctor who cared a patient with COVID-19 in Hospital A, in Wuhan, Hubei, China, which indicates existence of super-spreader during incubation period and sustained human-to-human transmission of COVID-19.

A 66-year-old woman (patient $A_{1}$ ) with a history of cholecystolithiasis presenting right epigastric pain, fever, and tenderness in the right upper abdomen was admitted by doctor $\mathrm{B}$ to department $\mathrm{A}$ for consideration of acute cholecystitis. During preoperative preparation, patient $A_{1}$

\footnotetext{
*Correspondence: zhenshun_cheng@126.com

1 Department of Pulmonary and Critical Care Medicine, Zhongnan Hospital of Wuhan University, No.169 Donghu Road, Wuhan 430071, China

Full list of author information is available at the end of the article
}

presented progressive dyspnea. Chest computed tomography $(\mathrm{CT})$ scan showed bilateral wide spread groundglass opacity at day 6 after admission. Then, real-time reverse transcription-polymerase chain reaction (RTPCR) of a throat swabs has been done and confirmed SARS-CoV-2 infection. Patient $\mathrm{A}_{1}$ was transferred immediately to isolation ward. Without realization of infectious disease, doctor B didn't use any personal protectives when provided health care for patient $\mathrm{A}_{1}$.

The exposure history was shown in Fig. 1. A multiple disciplinary team meeting (MDT) was hold by department $\mathrm{A}$ on the third day after doctor $\mathrm{B}$ first exposure to patient $A_{1}$. About 40 health-care workers (including doctor $\mathrm{B}-\mathrm{Q}$ and nurse $\mathrm{R}$ ) attended the MDT. The MDT lasted for about several hours in a closed meeting room. After the MDT, doctor F conducted a consultation for his patient. Doctor $\mathrm{S}$ and $\mathrm{T}$ from other two departments communicated with doctor $\mathrm{F}$ during the consultation for less than half an hour.

Within 10 days, 14 health care workers presented symptoms, such as fever, cough, fatigue, myalgia, etc. (Additional file 1: Table S1). Doctor $\mathrm{H}$ even felt unwell on the day after the MDT. Doctor B presented symptoms 3 days after the MDT. All 19 health-care workers had abnormal chest CT scan with ground-glass opacity and/ otherwise in a credit line to the material. If material is not included in the article's Creative Commons licence and your intended use is not permitted by statutory regulation or exceeds the permitted use, you will need to obtain permission directly from the copyright holder. To view a copy of this licence, visit http://creativecommons.org/licenses/by/4.0/. The Creative Commons Public Domain Dedication waiver (http://creativecommons.org/publicdomain/zero/1.0/) applies to the data made available in this article, unless otherwise stated in a credit line to the data. 


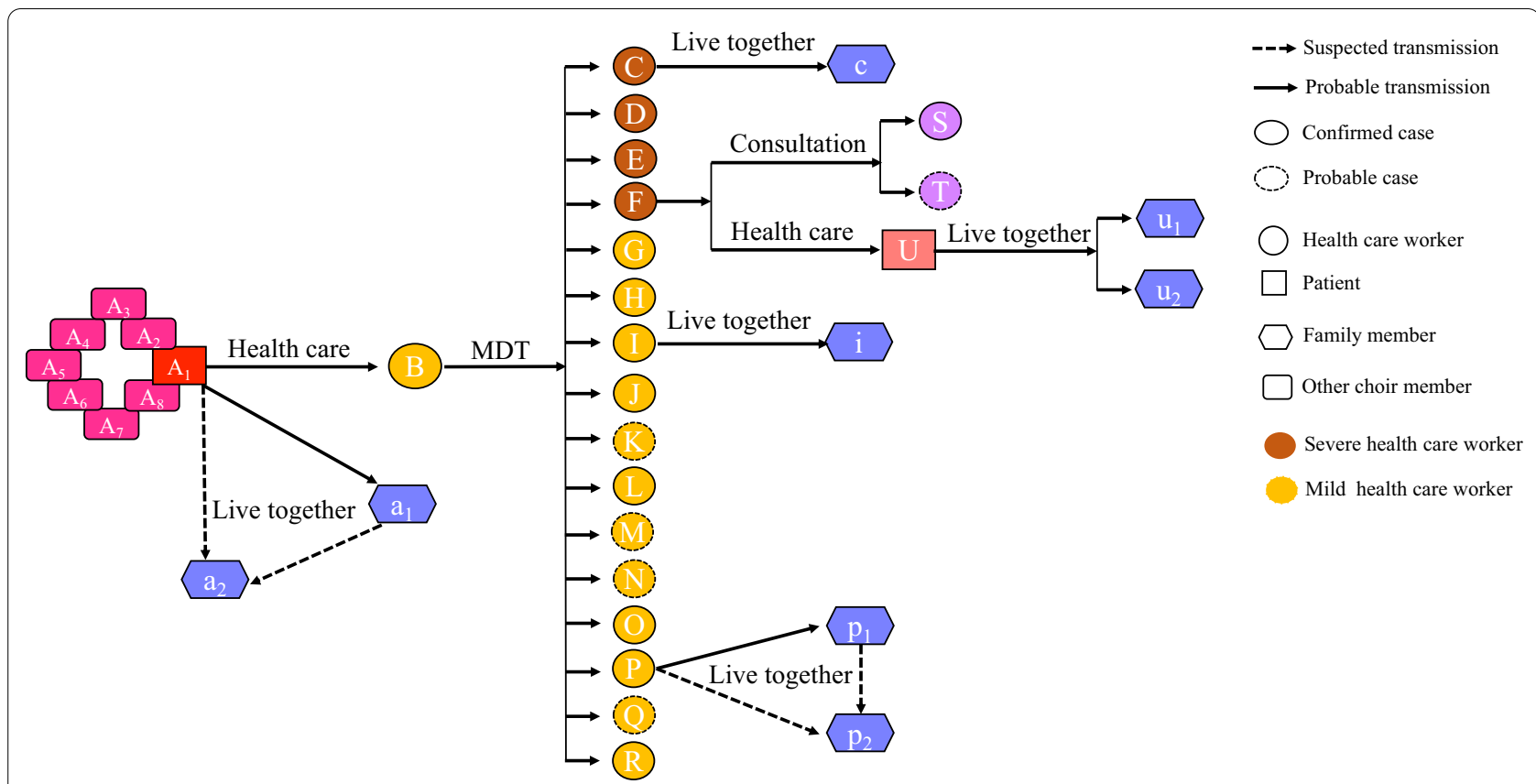

Fig. 1 Transmission map of outbreak of COVID-19. All confirmed cases and the five probable cases linked to transmission event are shown. Putative transmissions are indicated. The letters within symbols are health-care workers, patients, family members and choir members identifiers

or subsegmental areas of consolidation, but normal white blood cell counts and procalcitonin (PCT) values. Assays of SARS-CoV-2 by real-time RT-PCR from throat swabs samples were positive in 14 of 19 health-care workers (Additional file 1: Table S1). The 5 with negative nucleic acid test of SARS-CoV-2 all had abnormal chest CT scan with unilateral ground-glass opacity. The negative result of SARS-CoV-2 test may be explained by low viral load and only once nucleic acid test.

Afterwards, as shown in Fig. 1, the wife (c, i, $\left.\mathrm{p}_{1}\right)$ of doctor $\mathrm{C}, \mathrm{I}$, and $\mathrm{P}$ respective, the mother-in-law $\left(\mathrm{p}_{2}\right)$ of doctor $\mathrm{P}$ and a patient $(\mathrm{U})$ of doctor $\mathrm{F}$ were confirmed COVID-19. The wife $\left(\mathrm{u}_{1}\right)$ and mother $\left(\mathrm{u}_{2}\right)$ of patient $\mathrm{U}$ were also confirmed as COVID-19 later. In addition, patient $A_{1}$ was a member of a chorus in which they often sang together. Seven members $\left(A_{2}-A_{8}\right)$ of his choir were confirmed or suspected COVID-19 and two were died. The son $\left(a_{1}\right)$ of patient $A_{1}$ was also confirmed COVID-19 as well as his cousin $\left(a_{2}\right)$.

After inquiry of all the health-care workers attended the MDT, we learnt that doctor B was the only person who was definitely exposed to the person with confirmed COVID-19 before the MDT. Therefore, doctor B was the most possible source of SARS-CoV-2 in the health-care workers attended the MDT. The possibility that some health-care workers in the same department as doctor $B$ may be infected by doctor B during daily work cannot be precluded. It was reported that asymptomatic persons are potential sources of SARS-CoV-2 infection [3]. The MDT was hold 3 days before symptoms onset of doctor B. Doctor $B$ was in incubation period when attended the MDT. Whereas, doctor B was yet induced transmission of SARS-CoV-2 to 16 health-care workers. Thus, a person infected SARS-CoV-2 may be a 'super-spreader' even during incubation period. Indeed, the presence of 'superspreaders' of COVID-19 cannot be precluded in the large clinical research of Dr. Zhong's group [4]. Phenomenon of super-spreading was observed in SARS and MERS [5]. In addition, the third and fourth generation of COVID19 was detected in this case, which indicated possible sustained human-to-human transmission of COVID-19.

Among the 14 health-care workers who presented symptoms, the median incubation time was 4.0 days (IQR 2.0-6.0). However, the shortest incubation time observed in this case was less than 1 day, which is consistent to the recent large clinical research of Dr. Zhong's group [4].

\section{Supplementary information}

\section{Supplementary information accompanies this paper at https://doi. org/10.1186/s12931-020-01592-w.}

Additional file 1: Table S1. Characteristics of patient $A_{1}$ and health care workers with confirmed or suspected COVID-19. 


\section{Abbreviations}

COVID-19: Coronavirus disease 2019: SARS-CoV-2: Severe acute respiratory syndrome coronavirus 2; WHO: World Health Organization; CT: Computed tomography; RT-PCR: Reverse transcription-polymerase chain reaction; MDT: Multiple disciplinary team meeting; PCT: Procalcitonin; IQR: Interquartile range.

\section{Acknowledgements}

None reported.

\section{Authors' contributions}

$Y Y$ and $Z C$ had full access to all of the data in the study and take responsibility for the integrity of the data and the accuracy of the data analysis. CW is the first author. ZC and YY contributed equally to this article. Concept and design: ZC, CW. Acquisition, analysis, or interpretation of data: CW, ZC. Statistical analysis: CW. Drafting of the manuscript: CW. Critical revision of the manuscript for important intellectual content: ZC, YY. All authors read and approved the final manuscript.

\section{Funding}

Ministry of Science and Technology of the People's Republic of China (Grant No. 2020YFC0845500).

\section{Availability of data and materials}

The datasets used and/or analysed during the current study are available from the corresponding author on reasonable request.

\section{Ethics approval and consent to participate}

The study was approved by the institutional ethics board of Zhongnan Hospital of Wuhan University (No. 2020013). Oral consent was obtained from patients or their health care proxy.

\section{Consent for publication}

A consent form will be made available to the Editor if requested.

\section{Competing interests}

The authors declare that they have no competing interests.

\section{Author details}

${ }^{1}$ Department of Pulmonary and Critical Care Medicine, Zhongnan Hospital of Wuhan University, No.169 Donghu Road, Wuhan 430071, China. ${ }^{2}$ Department of Hepatobiliary Surgery, Zhongnan Hospital of Wuhan University, No.169 Donghu Road, Wuhan 430071, China. ${ }^{3}$ Wuhan Research Center for Infectious Diseases and Cancer, Chinese Academy of Medical Sciences, No.169 Donghu Road, Wuhan 430071, China.

Received: 3 April 2020 Accepted: 1 December 2020

Published online: 10 December 2020

\section{References}

1. Chan JF-W, Yuan S, Kok K-H, To KK-W, Chu H, Yang J, Xing F, Liu J, Yip CC-Y, Poon RW-S, et al. A familial cluster of pneumonia associated with the 2019 novel coronavirus indicating person-to-person transmission: a study of a family cluster. The Lancet. 2019;2020(395):514-23.

2. Li Q, Guan X, Wu P, Wang X, Zhou L, Tong Y, Ren R, Leung KSM, Lau EHY, Wong JY, et al. Early transmission dynamics in Wuhan, China, of novel coronavirus-infected pneumonia. N Engl J Med. 2020;382:1199-207.

3. Rothe C, Schunk M, Sothmann P, et al. Transmission of 2019-nCoV infection from an asymptomatic contact in Germany. N Engl J Med. 2020;382:970-1.

4. Guan W, Ni Z, Hu Y, Liang W, Ou C, He J, Liu L, Shan H, Lei C, Hui DSC, et al. Clinical characteristics of coronavirus disease 2019 in China. N Engl J Med. 2020;382:1708-20.

5. Wong G, Liu W, Liu Y, Zhou B, Bi Y, Gao GF. MERS, SARS, and Ebola: the role of super-spreaders in infectious disease. Cell Host Microbe. 2015;18:398-401

\section{Publisher's Note}

Springer Nature remains neutral with regard to jurisdictional claims in published maps and institutional affiliations.
Ready to submit your research? Choose BMC and benefit from:

- fast, convenient online submission

- thorough peer review by experienced researchers in your field

- rapid publication on acceptance

- support for research data, including large and complex data types

- gold Open Access which fosters wider collaboration and increased citations

- maximum visibility for your research: over $100 \mathrm{M}$ website views per year

At BMC, research is always in progress.

Learn more biomedcentral.com/submissions 